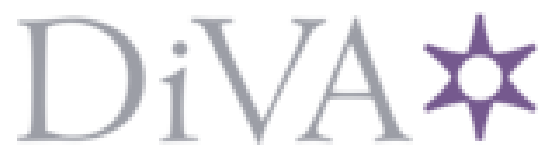

http://www.diva-portal.org

This is the published version of a paper published in Organic Letters.

Citation for the original published paper (version of record):

Lindstedt, E., Stridfeldt, E., Olofsson, B. (2016)

Mild Synthesis of Sterically Congested Alkyl Aryl Ethers.

Organic Letters, 18(17): 4234-4237

https://doi.org/10.1021/acs.orglett.6b01975

Access to the published version may require subscription.

N.B. When citing this work, cite the original published paper.

Permanent link to this version:

http://urn.kb.se/resolve?urn=urn:nbn:se:su:diva-135023 


\title{
Mild Synthesis of Sterically Congested Alkyl Aryl Ethers
}

\author{
Erik Lindstedt, Elin Stridfeldt, and Berit Olofsson* \\ Department of Organic Chemistry, Arrhenius Laboratory, Stockholm University, SE-106 91 Stockholm, Sweden
}

\section{Supporting Information}

ABSTRACT: An efficient and transition-metal-free method is presented to access tertiary alkyl aryl ethers by arylation of tertiary alcohols with ortho-substituted diaryliodonium salts. The scope covers cyclic and acyclic aliphatic, benzylic, allylic, and propargylic tertiary alcohols as well as primary and secondary fluorinated alcohols. The methodology gives access to alkyl aryl ethers of previously unprecedented steric congestion. Furthermore, the versatility of the developed procedure was demonstrated by arylation of the pro-drug mestranol.

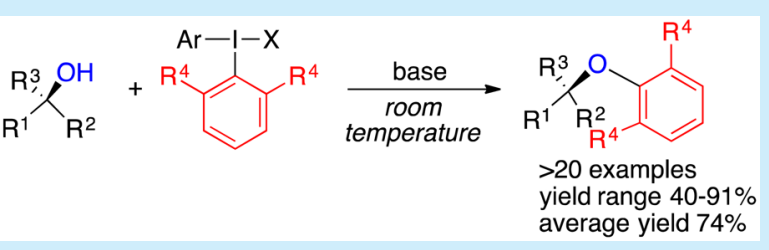

$\mathrm{T}$ he synthesis of ethers and functionalization of alcohols are broad research areas due to the prevalent occurrence of these compound classes as both starting materials and products in Nature and pharmaceuticals. However, traditional methods for synthesis of alkyl aryl ethers are all associated with difficulties, and the arylation of tertiary alcohols with electron-rich or sterically hindered arenes to obtain highly sterically hindered ethers is severely limited (Scheme 1a). ${ }^{1}$ Among the methods

Scheme 1. Synthesis of Sterically Hindered Alkyl Aryl Ethers

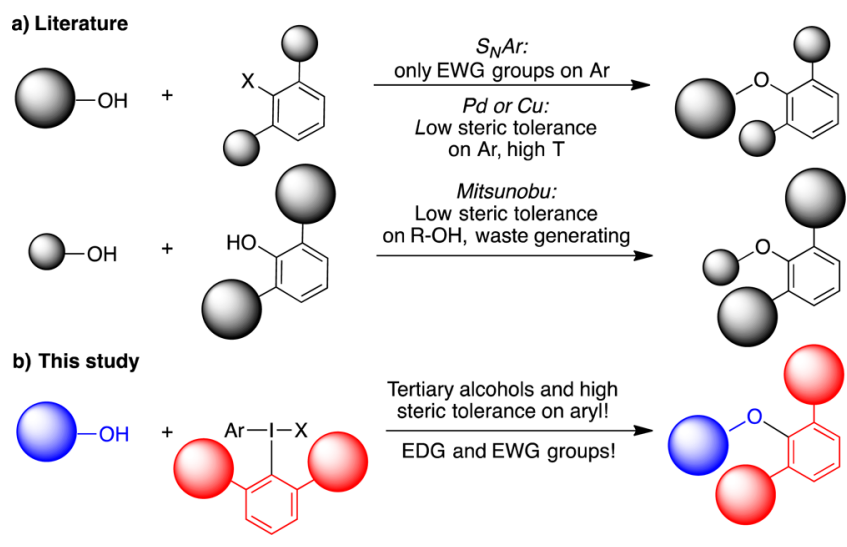

based on arylation of alcohols, $S_{N} A r$ reactions can be used. ${ }^{2}$ The method tolerates sterically congested alcohols as well as orthosubstituted arenes, but the scope is limited to arenes activated by electron-withdrawing groups. Another approach is via aryne-type intermediates, which generally suffer from regioselectivity issues and the lack of bis-ortho substituent patterns. ${ }^{3}$ While some transition-metal-catalyzed methodologies are compatible with tertiary alcohols, the combination of such substrates with orthosubstituted aryl groups remains difficult, and examples with bisortho-substituted aryl groups are lacking. ${ }^{4}$ Furthermore, these methods usually require high temperatures and have problems associated with remaining traces of transition metals.

Alternatively, Mitsunobu-type reactions can be applied, which are limited by steric bulk on the alcohol and by the formation of waste. ${ }^{5}$ Addition to alkenes is another strategy to obtain sterically hindered alkyl aryl ethers. Such reactions require transition metals or acidic conditions and are usually intramolecular. ${ }^{1 \mathrm{a}, 6}$ Development of new methodologies is hence required to obtain highly sterically congested aryl ethers.

Diaryliodonium salts are reactive, electrophilic arylation reagents that have been utilized to arylate a wide range of nucleophiles in recent years. ${ }^{7}$ Many developed methodologies for $O$-arylation with these hypervalent iodine reagents have a broad scope, both in terms of nucleophiles and aryl groups. However, the formation of alkyl aryl ethers from aliphatic alcohols has proved problematic and sensitive to steric hindrance. ${ }^{8}$ While primary alcohols react well, and secondary alcohols with some limitations, there are only two reported examples with tertiary alcohols, using an electron-withdrawing nitro group on the diaryliodonium salt to facilitate the reaction. $^{8 \mathrm{~d}, \mathrm{e}}$ Arylation of aliphatic alcohols with electrondonating diaryliodonium salts has also been challenging and often results in complex mixtures due to aryne formation.

Our research group has had a long-term interest in the synthesis and applications of diaryliodonium salts, ${ }^{10}$ and we set out to develop a methodology that enables synthesis of sterically congested alkyl aryl ethers by arylation of tertiary alcohols with ortho-substituted diaryliodonium salts (Scheme $1 \mathrm{~b}$ ).

As a model reaction, the arylation of tert-butoxides $(t-\mathrm{BuOZ})$ with dimesityliodonium salts $\left(\mathrm{Mes}_{2} \mathrm{IX}, \mathbf{1 a}\right)$ to reach mesitylated ether 2a was initially screened (Table 1). To our delight, 2a was formed in good yield at room temperature. ${ }^{11}$ Such an electronrich and sterically hindered aryl group has not previously been transferred to an aliphatic alcohol using diaryliodonium salts. ${ }^{12}$ The cation $\mathbf{Z}$ markedly influenced the outcome, and $t$ - $\mathrm{BuOLi}$ was considerably inferior to $t$-BuOK and $t$-BuONa (entries 1-3). The solvent had a major impact on the reaction (entries 1, 4-7), and the nonpolar solvent pentane was selected for further screening (entries 7-15).

Received: July 7, 2016

Published: August 16, 2016 
Table 1. Investigation of the Counterion Effect

\begin{tabular}{|c|c|c|c|c|c|}
\hline & $\mathrm{J}^{-} \mathrm{z}^{+}$ & $\begin{array}{c}\text { Mes-I-X } \\
\text { Mes } \\
\mathbf{1 a - X}\end{array}$ & $\frac{\text { solvent }}{\mathrm{rt} \text {, time }}$ & & \\
\hline entry & anion $\mathbf{X}$ & $t$-BuOZ (equiv) & solvent & time $(\mathrm{h})$ & yield $^{a}(\%)$ \\
\hline 1 & OTf & $\mathrm{K}, 1$ & toluene & 24 & 62 \\
\hline 2 & OTf & $\mathrm{Na}, 1$ & toluene & 24 & 53 \\
\hline 3 & OTf & $\mathrm{Li}, 1$ & toluene & 24 & 10 \\
\hline 4 & OTf & $\mathrm{K}, 1$ & TBME & 24 & 53 \\
\hline 5 & OTf & $\mathrm{K}, 1$ & THF & 24 & 9 \\
\hline 6 & OTf & $\mathrm{K}, 1$ & $\mathrm{MeCN}$ & 24 & 0 \\
\hline 7 & OTf & $\mathrm{K}, 1$ & pentane & 24 & 71 \\
\hline 8 & OTf & $\mathrm{Na}, 1$ & pentane & 24 & 62 \\
\hline $9^{b}$ & OTf & $\mathrm{Li}, 1$ & heptane & 24 & 56 \\
\hline 10 & $\mathrm{BF}_{4}$ & $\mathrm{Na}, 1$ & pentane & 24 & 73 \\
\hline 11 & $\mathrm{BF}_{4}$ & $\mathrm{Na}, 2$ & pentane & 1 & 91 \\
\hline 12 & $\mathrm{Br}$ & $\mathrm{Na}, 2$ & pentane & 1 & 85 \\
\hline 13 & OTs & $\mathrm{Na}, 2$ & pentane & 1 & 79 \\
\hline 14 & OTf & $\mathrm{Na}, 2$ & pentane & 1 & 60 \\
\hline 15 & OTf & $\mathrm{K}, 2$ & pentane & 1 & 76 \\
\hline
\end{tabular}

${ }^{a} 0.2 \mathrm{mmol}$ scale, $0.2 \mathrm{M} ;{ }^{1} \mathrm{H}$ NMR yields with 1,3,5-trimethoxybenzene as internal standard. ${ }^{b}$ at $110^{\circ} \mathrm{C}, 0.05 \mathrm{M}$.

The same cation trend was observed in pentane (entries 7 and 8 ), and product formation in reactions with $t$-BuOLi was enabled by increasing the temperature and decreasing the concentration (entry 9). ${ }^{11}$ The tetrafluoroborate salt $\mathbf{1 a}-\mathbf{B F}_{4}$ proved as efficient with $t$-BuONa, providing $2 \mathrm{a}$ in $73 \%$ yield (entries 7 and 10 ). Ether $2 \mathrm{a}$ was obtained in $91 \%$ yield within $1 \mathrm{~h}$ when 2 equiv of $t$ $\mathrm{BuONa}$ was employed (entry 11). This efficiency was also observed with other anions $\mathbf{X}$ (entries 12-13), although the triflate salt worked best with $t$-BuOK (entries 14 and 15). Presently, we have no explanation for the observed ion effects.

The chemoselectivity in reactions with unsymmetric diaryliodonium salts was investigated with salt $\mathbf{1 b}$ having a trimethoxyphenyl (TMP) ligand as "dummy group" (Scheme 2 ). The reaction was performed on a $5 \mathrm{mmol}$ scale without

Scheme 2. Large-Scale, Chemoselective Arylation

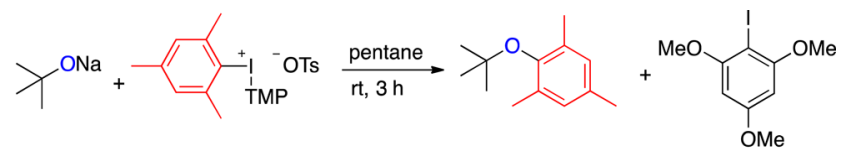

$\begin{array}{llll}(10 \mathrm{mmol}) & \text { 1b }(5 \mathrm{mmol}) & \text { 2a } 86 \% & \text { TMP-l } 89 \%\end{array}$

detectable transfer of the TMP group, delivering $\mathbf{2 a}$ in high yield with TMP-I as the easily isolable iodoarene. Salts with the TMP dummy group are efficiently synthesized and have previously been reported as highly chemoselective. ${ }^{13}$ In the present reaction, the advantage of using $\mathbf{1 b}$ over mesityl salt $\mathbf{1 a}$ resides in the facile separation of TMP-I from the product.

The arylation scope was screened with various orthosubstituted symmetric and unsymmetric diaryliodonium salts with $3 \mathrm{~h}$ reaction time to ensure full conversion into the tert-butyl aryl ethers 2 (Scheme 3 ). ${ }^{14}$ The mesitylated product $\mathbf{2 a}$ was synthesized using either salt $\mathbf{1 a}$ or $\mathbf{1} \mathbf{b}$, with $\mathbf{1 b}$ proving slightly better. 2,6-Dimethyl product $\mathbf{2} \mathbf{b}$ was formed with similar efficacy. Halide substituents were well tolerated, and bromo ether $2 \mathrm{c}$ was efficiently obtained using an unsymmetric TMP salt (1c) that
Scheme 3. Arylation Scope ${ }^{a}$

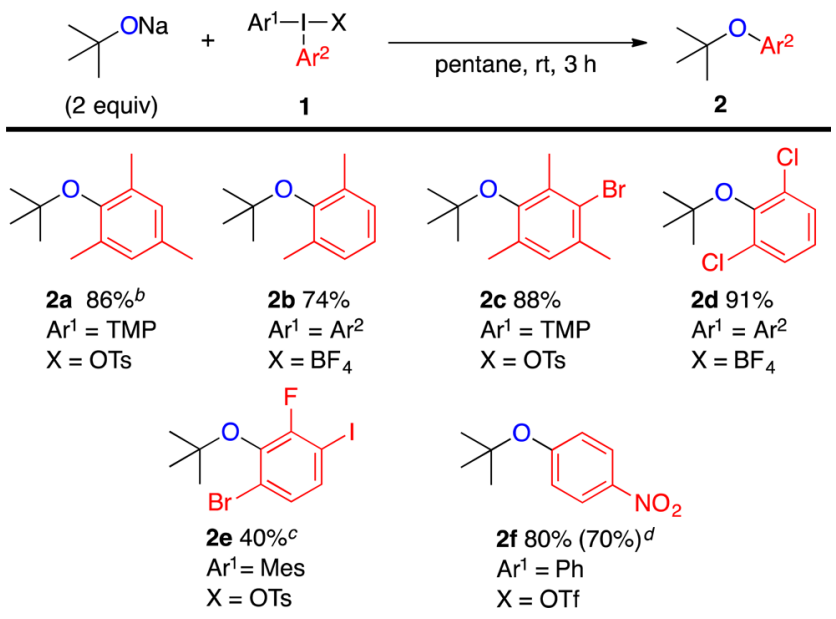

${ }^{a}$ Conditions: $\operatorname{Ar}_{2} \mathrm{IX} 1$ ( $\left.0.5 \mathrm{mmol}\right), t$-BuONa (2 equiv), pentane $(2.5$ $\mathrm{mL}) .{ }^{b} 5 \mathrm{mmol}$ scale. ${ }^{c}$ Toluene, $24 \mathrm{~h}$, crude NMR ratio $2.8: 1$ of $2 \mathrm{e}: 2 \mathrm{a}$. ${ }^{d}$ In toluene, see ref $8 \mathrm{~d}$.

chemoselectively transferred the more electron-deficient aryl group in high yield.

Likewise, the 2,6-dichloro-substituted product $\mathbf{2 d}$ was formed in excellent yield. To show the versatility of the reaction, we synthesized ether $\mathbf{2 e}$, carrying three different halides suitable for further transformations, using an unsymmetric salt with a mesityl dummy group. While Stuart and co-workers have used the mesityl group as a dummy ligand for the arylation of secondary alcohols, ${ }^{8 \mathrm{e}}$ we obtained a separable mixture of ethers under our reaction conditions. ${ }^{11}$ Nitro-substituted ether $\mathbf{2 f}$ was formed in higher yield than with our previous methodology, ${ }^{8 \mathrm{~d}}$ illustrating that the present conditions are preferable also with reactive, electron-deficient diaryliodonium triflates.

The arylation of a range of tertiary alcohols 3 was subsequently investigated (Scheme 4a). 2-Phenylpropan-2-ol was selected as model substrate, and a brief screening of bases revealed that NaHMDS was best. With this base, the mesitylated product $4 \mathbf{a}$ was easily isolated in high yield, without the need for excess reagents. ${ }^{11}$ The dichloro-substituted ether $4 \mathbf{b}$ was formed in equally good yield, despite the acid-sensitive nature of this compound. The unsymmetric, bromo-substituted salt 1c displayed the same high degree of chemoselectivity as before, delivering ether $4 \mathrm{c}$ in high yield.

Several different alcohols were then screened. To our delight, the highly sterically hindered substrate 1,1-diphenylethan-1-ol smoothly delivered the ether product 4d. Reactions with triphenylmethanol, with further increased steric congestion, failed to give any desired product. 1-Methylcyclohexanol was mesitylated to $4 \mathbf{e}$ in moderate yield with salt $\mathbf{1 b}$; the isolated yield increased to 59\% using salt 1a. Furthermore, severely sterically hindered acyclic alcohols underwent the reaction with ease, delivering $\mathbf{4 f}$,g in good yields. A tertiary allylic alcohol was also well tolerated, delivering the mesitylated product $\mathbf{4 h}$.

Propargylic alcohols are an interesting class of alcohols that can undergo a large set of transformations. Propargyl aryl ethers are usually synthesized by substitution reactions using a phenol as the nucleophile. ${ }^{15}$ The formed ethers can be ring-closed to give chromenes, which are precursors to biologically active coumarins. ${ }^{16}$ Primary propargylic alcohols were recently arylated with diaryliodonium salts. ${ }^{17}$ 
Scheme 4. Alcohol Scope ${ }^{a}$

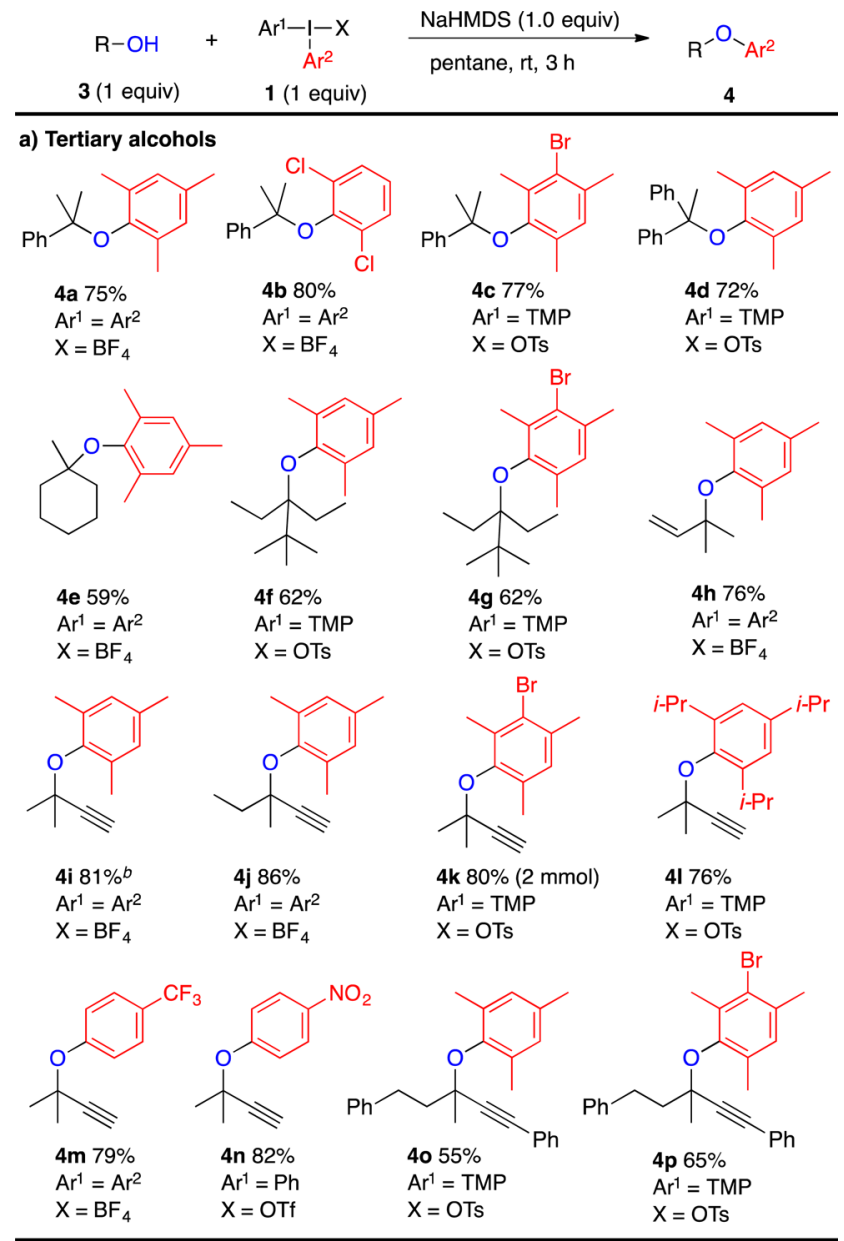

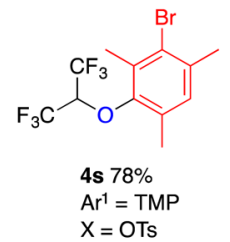

${ }^{a}$ Conditions: $\operatorname{Ar}_{2} \mathrm{IX} 1$ ( $\left.0.5 \mathrm{mmol}\right)$, alcohol 3 (1 equiv), NaHMDS (1 equiv), pentane $(2.5 \mathrm{~mL}) .{ }^{b} 1 \mathrm{mmol}$ scale.

When tertiary propargylic alcohols were subjected to our optimized conditions, the arylated products $4 \mathbf{i}-\mathbf{l}$ were obtained in high yields. The reaction could easily be scaled up to $2 \mathrm{mmol}$ with maintained yield and excellent chemoselectivity (4k). Notably, even the highly sterically congested triisopropylphenyl group was efficiently transferred to give product 41 in good yield. This further demonstrates the usefulness of diaryliodonium salts as group-transfer reagents of highly sterically hindered aryl moieties. Protection of the alkyne was not necessary, hence allowing for further transformations in a straightforward fashion. Another advantage with this methodology to obtain propargyl aryl ethers, compared to substitution reactions, is that the stereochemistry is retained. ${ }^{8 \mathrm{~d}, 10 \mathrm{~b}}$

We briefly investigated the arylation of the propargylic alcohols with unhindered, para-substituted diaryliodonium salts. Reactions with $p$-Br- and $p$-t-Bu-substituted salts afforded regioisomeric mixtures, indicating that arynes were formed as intermediates. ${ }^{9 a, d}$ To our delight, the $\mathrm{CF}_{3}$-substituted ether $4 \mathrm{~m}$ and the nitro-substituted $4 \mathrm{n}$ were obtained with complete regioselectivity, highlighting that electron-deficient, unhindered diaryliodonium salts are suitable for arylation of tertiary alcohols. Internal alkyne substrates derived from alkynylation of ketones were also suitable substrates, delivering 4o,p.

Having achieved the goal of developing methodology for arylation of tertiary alcohols, we applied the optimized conditions to primary and secondary alcohols. While benzyl alcohol and 1-phenylethanol performed poorly, alcohols with lower $\mathrm{p} K_{\mathrm{a}}$ were well tolerated (Scheme $4 \mathrm{~b}$ ). Trifluoroethanol was mesitylated to give $\mathbf{4 q}$ and bromomesitylated to give $4 \mathbf{r}$ in good yield with excellent chemoselectivity. Likewise, 2-hexafluoropropanol underwent the reaction smoothly, allowing efficient access to ether $4 \mathbf{s}$. Facile functionalization of this fluorinated substrate class could be of high interest, for example, in the pharmaceutical industry.

Derivatization of complex alcohols provides novel products with potentially interesting biological properties. Arylation of the pro-drug mestranol was hence undertaken as a proof of concept of the sterical bulk tolerated in the methodology. Under the standard reaction conditions, the mesitylated ether $4 \mathbf{t}$ was isolated in 64\% yield (Scheme 5).

\section{Scheme 5. Arylation of the Pro-drug Mestranol}

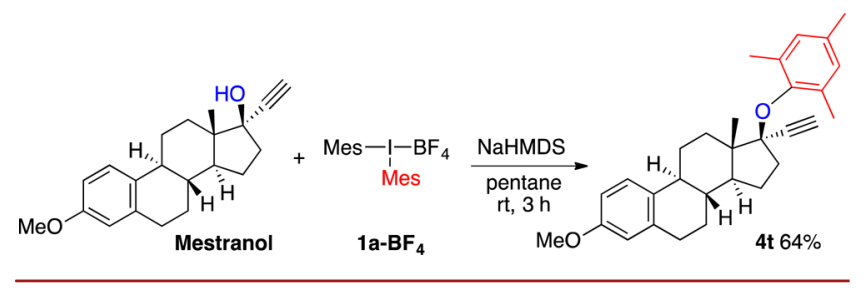

To conclude, transition-metal-free methodology to access sterically hindered alkyl aryl ethers by arylation of tertiary alcohols with ortho-substituted diaryliodonium salts has been developed. The substrate scope includes cyclic, acyclic, propargylic, and allylic alcohols. The methodology has been extended to arylation of fluorinated primary and secondary alcohols and to arylations with electron-deficient parasubstituted diaryliodonium salts. The straightforward derivatization of the pro-drug mestranol illustrates the utility of the presented methodology. A detailed mechanistic study of $O$ arylations with diaryliodonium salts is currently ongoing in our laboratory to understand the limitations in reactions with orthounsubstituted electron-rich diaryliodonium salts.

\section{ASSOCIATED CONTENT}

\section{Supporting Information}

The Supporting Information is available free of charge on the ACS Publications website at DOI: 10.1021/acs.orglett.6b01975.

Experimental details and spectral data for novel compounds, as well as NMR spectra of all products (PDF)

\section{AUTHOR INFORMATION}

\section{Corresponding Author}

*E-mail: berit.olofsson@su.se.

\section{Notes}

The authors declare no competing financial interest. 


\section{ACKNOWLEDGMENTS}

The Swedish Research Council (621-2011-3608 and 201504404) is kindly acknowledged for financial support.

\section{REFERENCES}

(1) Steric hindrance is tolerated on the arene or on the alcohol, but few reports tolerate a combination of the two: (a) Hu, N.; Li, K.; Wang, Z.; Tang, W. Angew. Chem., Int. Ed. 2016, 55, 5044-5048. Addition of $\mathrm{RMgX}$ to $o$-quinol acetates delivers sterically hindered ethers in moderate yields: (b) Miller, B. J. Org. Chem. 1977, 42, 1402-1408.

(2) (a) Woiwode, T. F.; Rose, C.; Wandless, T. J. J. Org. Chem. 1998, 63, 9594-9596. (b) Henderson, A. S.; Medina, S.; Bower, J. F.; Galan, M. C. Org. Lett. 2015, 17, 4846-4849. (c) Engle, K. M.; Luo, S.-X.; Grubbs, R. H. J. Org. Chem. 2015, 80, 4213-4220.

(3) Dong, Y.; Lipschutz, M. I.; Tilley, T. D. Org. Lett. 2016, 18, 15301533.

(4) (a) Wu, X.; Fors, B. P.; Buchwald, S. L. Angew. Chem., Int. Ed. 2011, 50, 9943-9947. (b) Shafir, A.; Lichtor, P. A.; Buchwald, S. L. J. Am. Chem. Soc. 2007, 129, 3490-3491. (c) Altman, R. A.; Shafir, A.; Choi, A.; Lichtor, P. A.; Buchwald, S. L. J. Org. Chem. 2008, 73, 284-286. (d) Wolter, M.; Nordmann, G.; Job, G. E.; Buchwald, S. L. Org. Lett. 2002, 4, 973-976. (e) Gowrisankar, S.; Sergeev, A. G.; Anbarasan, P.; Spannenberg, A.; Neumann, H.; Beller, M. J. Am. Chem. Soc. 2010, 132, 11592-11598. (f) Shelby, Q.; Kataoka, N.; Mann, G.; Hartwig, J. J. Am. Chem. Soc. 2000, 122, 10718-10719. (g) Parrish, C. A.; Buchwald, S. L. J. Org. Chem. 2001, 66, 2498-2500. (h) Wang, H.; Li, G.; Engle, K. M.; Yu, J.-Q.; Davies, H. M. L. J. Am. Chem. Soc. 2013, 135, 6774-6777. (i) Wang, X.; Lu, Y.; Dai, H.-X.; Yu, J.-Q. J. Am. Chem. Soc. 2010, 132, 12203-12205.

(5) (a) Liu, D.; Sanow, L. P.; Zhang, C. Tetrahedron Lett. 2014, 55, 3090-3092. (b) Swamy, K. C. K.; Kumar, N. N. B.; Balaraman, E.; Kumar, K. V. P. P. Chem. Rev. 2009, 109, 2551-2651. (c) Lepore, S. D.; He, Y. J. Org. Chem. 2003, 68, 8261-8263.

(6) (a) Li, W.; Zhang, J., 4.05 Addition of HX Reagents to Alkenes, Alkynes, and Allenes without Transition Metal. In Comprehensive Organic Synthesis, 2nd ed.; Molander, G. A., Knochel, P., Eds.; Elsevier: Amsterdam, 2014; Vol. 4, pp 342-391. (b) Yang, C.-G.; He, C. J. Am. Chem. Soc. 2005, 127, 6966-6967.

(7) (a) Olofsson, B. Top. Curr. Chem. 2016, 373, 135-166. (b) Aradi, K.; Tóth, B. L.; Tolnai, G. L.; Novák, Z. Synlett 2016, 27, 1456-1485. (c) Merritt, E. A.; Olofsson, B. Angew. Chem., Int. Ed. 2009, 48, 90529070. (d) Yusubov, M. S.; Maskaev, A. V.; Zhdankin, V. V. ARKIVOC 2011, i, 370-409.

(8) (a) Lubinkowski, J. J.; Gimenez Arrieche, C.; McEwen, W. E. J. Org. Chem. 1980, 45, 2076-2079. (b) Lubinkowski, J. J.; Knapczyk, J. W.; Calderon, J. L.; Petit, L. R.; McEwen, W. E. J. Org. Chem. 1975, 40, 3010-3015. (c) Lindstedt, E.; Ghosh, R.; Olofsson, B. Org. Lett. 2013, 15, 6070-6073. (d) Ghosh, R.; Lindstedt, E.; Jalalian, N.; Olofsson, B. ChemistryOpen 2014, 3, 54-57. (e) Sundalam, S. K.; Stuart, D. R. J. Org. Chem. 2015, 80, 6456-6466.

(9) Formation of arynes from diaryliodonium salts is known; see: (a) Wang, B.; Graskemper, J. W.; Qin, L.; DiMagno, S. G. Angew. Chem., Int. Ed. 2010, 49, 4079-4083. (b) Graskemper, J. W.; Wang, B.; Qin, L.; Neumann, K. D.; DiMagno, S. G. Org. Lett. 2011, 13, 3158-3161. (c) Ghosh, R.; Olofsson, B. Org. Lett. 2014, 16, 1830-1832. During the preparation of this paper, the synthetic use of these aryne intermediates was reported; see: (d) Sundalam, S. K.; Nilova, A.; Seidl, T. L.; Stuart, D. R. Angew. Chem., Int. Ed. 2016, 55, 8431-8434. We have performed a detailed mechanistic study of aryne formation, the results of which will be reported shortly.

(10) (a) Ghosh, R.; Stridfeldt, E.; Olofsson, B. Chem. - Eur. J. 2014, 20, 8888-8892. (b) Jalalian, N.; Petersen, T. B.; Olofsson, B. Chem. - Eur. J. 2012, 18, 14140-14149. (c) Reitti, M.; Villo, P.; Olofsson, B. Angew. Chem., Int. Ed. 2016, 55, 8928-8932. (d) Tinnis, F.; Stridfeldt, E.; Lundberg, H.; Adolfsson, H.; Olofsson, B. Org. Lett. 2015, 17, 26882691.

(11) See the Supporting Information for more details.
(12) The mesityl group has previously been used as a "dummy" ligand (i.e., not been transferred) in arylation of alcohols; see ref 8e. In parallel with this study, we developed the $\mathrm{O}$-arylation of carbohydrates, which chould also be mesitylated: Tolnai, G. L.; Nilsson, U. J.; Olofsson, B. Angew. Chem., Int. Ed. 2016, DOI: 10.1002/anie.201605999.

(13) (a) Malmgren, J.; Santoro, S.; Jalalian, N.; Himo, F.; Olofsson, B. Chem. - Eur. J. 2013, 19, 10334-10342. (b) Seidl, T. L.; Sundalam, S. K.; McCullough, B.; Stuart, D. R. J. Org. Chem. 2016, 81, 1998-2009.

(14) The salts were synthesized according to: (a) Zhu, M.; Jalalian, N.; Olofsson, B. Synlett 2008, 2008, 592-596. (b) Bielawski, M.; Aili, D.; Olofsson, B. J. Org. Chem. 2008, 73, 4602-4607. (c) Bielawski, M.; Zhu, M.; Olofsson, B. Adv. Synth. Catal. 2007, 349, 2610-2618. Bromide salts were avoided, as competing formation of bromoarene can complicate recycling of the formed iodoarene.

(15) (a) Banday, A. H.; Shameem, S. A.; Gupta, B. D.; Kumar, H. M. S. Steroids 2010, 75, 801-804. (b) Nishibayashi, Y.; Milton, M. D.; Inada, Y.; Yoshikawa, M.; Wakiji, I.; Hidai, M.; Uemura, S. Chem. - Eur. J. 2005, 11, 1433-1451. (c) Anderson, J. C.; McCarthy, R. A.; Paulin, S.; Taylor, P. W. Bioorg. Med. Chem. Lett. 2011, 21, 6996-7000. (d) Godfrey, J. D., Jr; Mueller, R. H.; Sedergran, T. C.; Soundararajan, N.; Colandrea, V. J. Tetrahedron Lett. 1994, 35, 6405-6408.

(16) (a) Majumdar, N.; Paul, N. D.; Mandal, S.; de Bruin, B.; Wulff, W. D. ACS Catal. 2015, 5, 2329-2366. (b) Tahtaoui, C.; Demailly, A.; Guidemann, C.; Joyeux, C.; Schneider, P. J. Org. Chem. 2010, 75, 37813785. (c) Elomri, A.; Mitaku, S.; Michel, S.; Skaltsounis, A.-L.; Tillequin, F.; Koch, M.; Pierré, A.; Guilbaud, N.; Léonce, S.; Kraus-Berthier, L.; Rolland, Y.; Atassi, G. J. Med. Chem. 1996, 39, 4762-4766. (d) Yan, K.; Yang, D.; Wei, W.; Wang, F.; Shuai, Y.; Li, Q.; Wang, H. J. Org. Chem. 2015, 80, 1550-1556.

(17) Sasaki, T.; Miyagi, K.; Moriyama, K.; Togo, H. Org. Lett. 2016, 18, 944-947. 